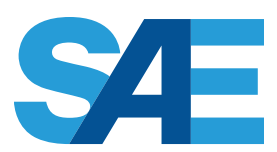

INTERNATIONAL

\title{
Modeling of Heating and Evaporation of FACE I Gasoline Fuel and its Surrogates
}

\section{Ahmed Elwardany}

KAUST, Alexandria University

\section{Jihad Badra}

Saudi Aramco

\section{Jaeheon Sim, Muneeb Khurshid, Mani Sarathy, and Hong Im \\ KAUST}

CITATION: Elwardany, A., Badra, J., Sim, J., Khurshid, M. et al., "Modeling of Heating and Evaporation of FACE I Gasoline Fuel and its Surrogates," SAE Technical Paper 2016-01-0878, 2016, doi:10.4271/2016-01-0878.

\begin{abstract}
The US Department of Energy has formulated different gasoline fuels called "Fuels for Advanced Combustion Engines (FACE)" to standardize their compositions. FACE I is a low octane number gasoline fuel with research octane number (RON) of approximately 70. The detailed hydrocarbon analysis (DHA) of FACE I shows that it contains 33 components. This large number of components cannot be handled in fuel spray simulation where thousands of droplets are directly injected in combustion chamber. These droplets are to be heated, broken-up, collided and evaporated simultaneously. Heating and evaporation of single droplet FACE I fuel was investigated. The heating and evaporation model accounts for the effects of finite thermal conductivity, finite liquid diffusivity and recirculation inside the droplet, referred to as the effective thermal conductivity/effective diffusivity (ETC/ED) model. The temporal variations of the liquid mass fractions of the droplet components were used to characterize the evaporation process. Components with similar evaporation characteristics were merged together. A representative component was initially chosen based on the highest initial mass fraction. Three 6 components surrogates, Surrogate 1-3, that match evaporation characteristics of FACE I have been formulated without keeping same mass fractions of different hydrocarbon types. Another two surrogates (Surrogate 4 and 5) were considered keeping same hydrocarbon type concentrations. A distillation based surrogate that matches measured distillation profile was proposed. The calculated molar mass, hydrogen-to-carbon $(\mathrm{H} / \mathrm{C})$ ratio and RON of Surrogate 4 and distillation based one are close to those of FACE I.
\end{abstract}

\section{Introduction}

The fuels for advanced combustion engines (FACE) have been formulated by the US Department of Energy and Coordinating Research Council (CRC) to eliminate the effect of variation in fuel composition on the combustion characteristics and to study low emissions, high efficiency compression ignition engines [1]. FACE fuels are complex mixture of hydrocarbons [2]. Simulation of processes took place in internal combustion engine cycle is an essential tool in optimization of current engines and design of new engines. These processes include spray break-up, droplet heating, evaporation and collision. The large number of components in real fuels leads to high computational cost and considering all fuel components is not feasible in the near future [1]. Hence, reducing number of fuel components is essential. This reduction is based on replacing components of real fuel with a mixture of representative components that match different target properties [ $\underline{3}]$. These target properties include i) combustion characteristics (ignition delay time/ RON "research octane number", flame speed, H/C ratio "hydrogento-carbon", soot tendency and engine performance) $[\underline{4}, \underline{5}, \underline{6}, \underline{7}, \underline{8}, \underline{9}$, $\underline{10}$ ], ii) physical properties (density, lower heating value, distillation profile and heating and evaporation of single droplet) $[\underline{11}, \underline{12}, \underline{13}, \underline{14}]$. Surrogates developed to mimic combustion characteristics are referred to as "chemical surrogate" while those that mimic thermophysical characteristics are called "physical surrogate". The optimum surrogate is the one that mimic both combustion and thermo-physical characteristics. 
In direct injection "DI" engines, fuel is injected directly into the combustion chamber in the form of spray of hundreds of fuel droplets. Heating and evaporation of these droplets affects all simultaneous processes including break-up, collision and mixing of fuel vapor with ambient air [15]. Real fuels are complex mixture of different types of hydrocarbons. Models for multi-component fuels can be classified into two main groups. The first one is applicable to large number of components where the fuel composition is described by a continuous distribution function and referred to as continuous multi-component (CMC) model [ㅌ]. The second group is applicable to small number of individual components and called discrete multicomponent model (DCM) [17, 18]. This paper is focused on the second group and applied it to model heating and evaporation of single droplet of FACE I gasoline fuel. The evaporation characteristics of FACE I is then used to formulate a surrogate that mimic evaporation characteristics and different target properties.

\section{Models}

\section{Heating and Evaporation Model}

The analysis of heating and evaporation of single droplet of FACE I and its different proposed surrogate is based on the effective thermal conductivity/effective diffusivity "ETC/ED" model. The model accounts for finite thermal and mass diffusivities inside the droplet and recirculation inside droplet [17]. The heat conduction equation inside spherically-symmetric droplet can be presented as [19]:

$$
\frac{\partial \mathrm{T}}{\partial \mathrm{t}}=\alpha_{1}\left(\frac{\partial^{2} \mathrm{~T}}{\partial \mathrm{R}^{2}}+\frac{2}{\mathrm{R}} \frac{\partial \mathrm{T}}{\partial \mathrm{R}}\right)
$$

where $\alpha_{1}=\frac{k_{1}}{c_{1} \rho_{1}}$ is the thermal diffusivity, $k_{1}, c_{1}$ and $\rho_{1}$ are the thermal conductivity, specific heat capacity and density of the liquid, respectively, $\mathrm{t}$ is time and $\mathrm{R}$ is the distance from the center of the droplet. In the case of moving droplets, the liquid thermal conductivity is replaced by the effective thermal conductivity $\mathrm{k}_{\text {eff }}=$ $\chi_{\mathrm{T}} \mathrm{k}_{\mathrm{l}}$, where $\chi_{\mathrm{T}}=1.86+0.86 \tanh \left[2.225 \log _{10}\left(\mathrm{Pe}_{\mathrm{d}(1)} / 30\right)\right]$ increases from 1 to 2.72 when the liquid Peclet number. The analytical solution of this equation is developed by Sazhin et al. [19] and incorporated into a numerical code for heating and evaporation of mono-component droplets. For the case of multi-component fuel droplet, the species diffusion equation inside spherically-symmetric droplet can be presented as [17]:

$$
\frac{\partial \mathrm{Y}_{\mathrm{li}}}{\partial \mathrm{t}}=\mathrm{D}_{\mathrm{I}}\left(\frac{\partial^{2} \mathrm{Y}_{\mathrm{li}}}{\partial \mathrm{R}^{2}}+\frac{2}{\mathrm{R}} \frac{\partial \mathrm{Y}_{\mathrm{li}}}{\partial \mathrm{R}}\right)
$$

where $i \geq 1, Y_{l i}$ is the liquid mass fraction of species $i$, and $D_{1}$ is the liquid mass diffusivity. The analytical solution of Eq. (2) is given in Sazhin et al. [17]. The effect of recirculation in the moving droplet is taken into account by replacing $\mathrm{D}_{1}$ with $\mathrm{D}_{\text {eff }}=\chi_{\mathrm{Y}} \mathrm{D}_{1}$, where $\chi_{\mathrm{Y}}=1.86$ $+0.86 \tanh \left[2.225 \log _{10}\left(\operatorname{Re}_{\mathrm{d}(\mathrm{l})} \mathrm{Sc}_{\mathrm{d}(\mathrm{l})} / 30\right)\right]$ increases from 1 to 2.72 when $\mathrm{Re}_{\mathrm{d}(\mathrm{l})} \mathrm{Sc}_{\mathrm{d}(\mathrm{l})}$ increases from 0 to infinity. The Schmidt number is defined as $S c_{d(1)}=\frac{\mu_{1}}{\rho_{1} D_{1}}$. The total evaporation rate is given by the following equation [20] :

$$
\dot{m}_{d}=-2 \pi R_{d} D_{v} \rho_{g} B_{M} \mathrm{Sh}
$$

where $\rho_{g}$ is the gas density, $D_{v}$ is the binary diffusion coefficient of vapor in air, Sh is the Sherwood number and $B_{M}$ is the Spalding mass transfer number (see Abramzon and Sirignano [21]).The detailed algorithm of this numerical code is described in [22].

\section{Fuel Composition}

The detailed hydrocarbon analysis "DHA" of FACE I shows that it consists of 33 components from different types of hydrocarbons including n-paraffins, iso-paraffins, aromatics, naphthenes and olefins (see Table 1). The DHA shows that there is less than $0.16 \%$ mass fraction of unidentified compounds. These were added to other known components according to their mass fractions by normalization.

\section{Distillation Profile}

For current study, H/C ratio, PIONA, RON, MON, carbon types, density, molecular weight and advance distillation curve (ADC) has been selected as target properties when formulating distillation based surrogate. The DHA was used to calculate the PIONA, carbon type distribution, $\mathrm{H} / \mathrm{C}$ ratio, and average molecular weight for FACE I. The target distillation curve was measured using the advanced distillation curve (ADC) approach described by Bruno et al.[려]

The selected surrogate palette species include 2-methylbutane, 2-methylhexane, 1-hexene, n-heptane, 2,2,4-trimethylpentane, cyclohexane and toluene. The surrogate development methodology used determines the optimal surrogate composition by minimizing an objective function representing the difference between target properties of the real fuel and surrogate mixtures [12]. RON and MON calculation of surrogate fuels were calculated based on linear by mole fraction blending of constituent fuel species [24]. Methodology of carbon type classification of FACE I and surrogates is described elsewhere $[\underline{25}, \underline{26}]$. ADC and density of surrogate mixtures were calculated using REFPROP as described by Mueller at al. [르].

\section{Results}

Temporal variation of droplet surface temperature and radius due to heating and evaporation of single droplet of FACE I gasoline fuel is presented in Fig. 1. The ETC/ED model was used with the initial droplet radius and temperature equal to $10 \mu \mathrm{m}$ and $300 \mathrm{~K}$, respectively. The ambient air pressure and temperature were taken equal to $0.3 \mathrm{MPa}$ and $450 \mathrm{~K}$, respectively, while the relative velocity was set at $10 \mathrm{~m} / \mathrm{s}$. these conditions represent the ambient condition in HCCI engines [27]. All ambient conditions were assumed to be constant, and the effect of droplets on ambient air was ignored. Close to the end of evaporation, it is clear that there is another heat-up period as can be seen from droplet surface temperature. This heat-up period is for the heavier component that remains in the droplet. As primary reference fuel "PRF" is commonly used as gasoline fuel surrogate [28], a PRF70 was tested and plotted in Fig. 1. It can be noticed that the evaporation time predicted for droplet of PRF70 is $10 \%$ less than tis of FACE I and the predicted surface temperature for PRF70 is too far in the heating-up period from this of FACE I droplet. This difference will significantly affect the droplet break-up and collision process in fuel spray cases [15]. Hence, the chemical surrogate, PRF70, cannot be used to mimic thermo-physical target such as evaporation characteristics. 
Table 1. Mass fractions of the components of FACE I gasoline fuel.

\begin{tabular}{|c|c|c|c|}
\hline & Group & component & $\%$ mass fraction \\
\hline 1 & \multirow{4}{*}{ 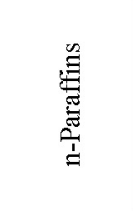 } & Propane & 0.06 \\
\hline 2 & & n-butane & 0.55 \\
\hline 3 & & n-pentane & 0.05 \\
\hline 4 & & n-heptane & 13.94 \\
\hline 5 & \multirow{17}{*}{ 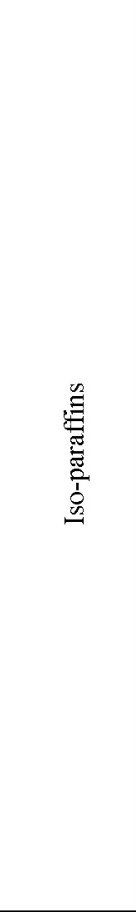 } & i-butane & 3.27 \\
\hline 6 & & i-pentane & 3.05 \\
\hline 7 & & 2,2 dimethyl butane & 0.28 \\
\hline 8 & & 2,3 dimethyl butane & 1.81 \\
\hline 9 & & 2 methylpentane & 5.55 \\
\hline 10 & & 3 methylpentane & 2.06 \\
\hline 11 & & 2,4 dimethylpentane & 2.22 \\
\hline 12 & & 2 methylhexane & 10.26 \\
\hline 13 & & 2,3 dimethylpentane & 6.40 \\
\hline 14 & & 3 methylhexane & 13.77 \\
\hline 15 & & 3 ethylpentane & 1.35 \\
\hline 16 & & $2,2,4$ trimethylpentane & 13.16 \\
\hline 17 & & 2,5 dimethylhexane & 1.07 \\
\hline 18 & & $2,2,3$ trimethylpentane & 0.32 \\
\hline 19 & & 2,4 dimethylhexane & 1.39 \\
\hline 20 & & 2,3,4 trimethlpentane & 3.62 \\
\hline 21 & & 2 methyl-3-ethylpentane & 1.01 \\
\hline 22 & \multirow{2}{*}{ Aromatics } & benzene & 0.75 \\
\hline 23 & & toluene & 3.87 \\
\hline 24 & \multirow{9}{*}{ 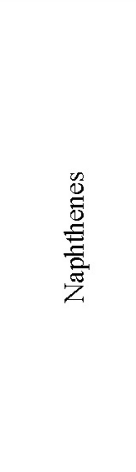 } & cyclopentane & 0.20 \\
\hline 25 & & 1,1 dimethylcyclopentane & 0.29 \\
\hline 26 & & $1 t, 3$ dimethylcyclopentane & 0.62 \\
\hline 27 & & 1c,3 dimethylcyclopentane & 0.66 \\
\hline 28 & & $1 t, 2$ dimethylcyclopentane & 0.81 \\
\hline 29 & & $1 \mathrm{c}, 2$ dimethylcyclopentane & 0.20 \\
\hline 30 & & methylcyclohexane & 0.47 \\
\hline 31 & & ethylcyclopentane & 0.13 \\
\hline 32 & & 2t-ethylmethylcyclopentane & 0.83 \\
\hline 33 & Olefins & Hexene-1 & 5.96 \\
\hline
\end{tabular}

The liquid mass fractions of the FACE I components at the surface of the droplet versus time for the same conditions as in Fig. 1 are shown in Fig. 2 with numbering of individual components as presented in Table 1. It can be seen that there are six groups of components that have similar evaporation characteristics. This can lead to reduction of the 33 components of FACE I to 6 components. Components with similar evaporation characteristics could be merged and represented by only one component. The component with highest initial mass fraction is chosen to be the representative component of its group except for the case of Fig. 3d, as both iso-octane (16) and n-heptane (4) are considered to formulate Surrogate 1 and Surrogate 2. Surrogate 3 is the same as Surrogate 2 but with replacing 3 methylhexane with 2,3 dimethyl pentane. In the first 3 surrogates, the mass fractions of different type of hydrocarbons are not kept similar to those of FACE I fuel. Surrogate 4 is 8 component surrogate that keep mass fractions different hydrocarbon types of the surrogate similar to those of FACE I fuel. Surrogate 5 is a trial to reduce the number of components of Surrogate 4 to 7 components by merging 2,3,4 trimethylpentane with 2,2,4 trimethylpentane. The mass and molar fractions of all considered surrogates are presented in Table 2.

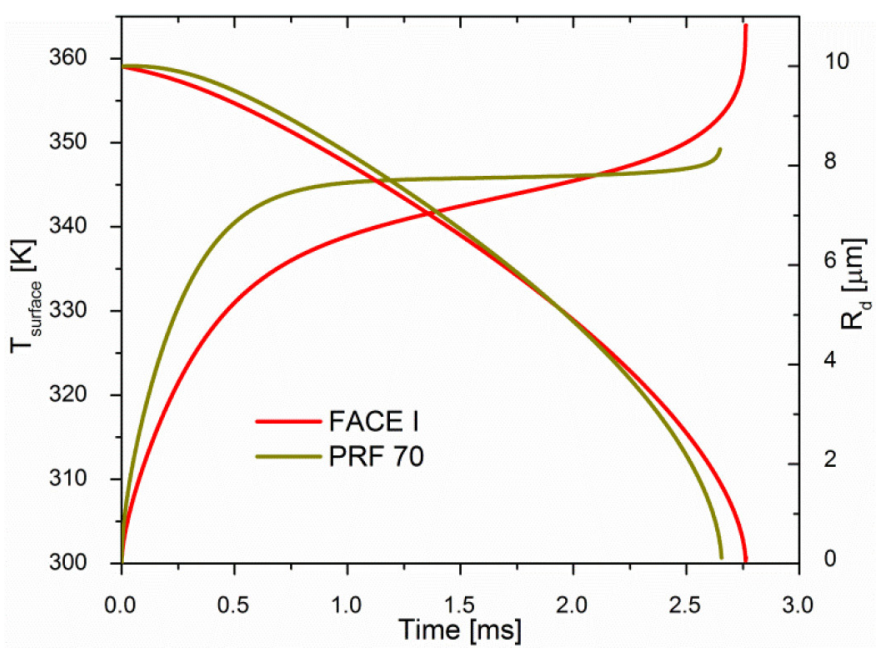

Figure 1. Time evolution of the surface temperatures and radii predicted by the ETC/ED model for FACE I and PRF 70 fuel droplets; the gas temperature and pressure are assumed to be constant and equal to $450 \mathrm{~K}$ and $0.3 \mathrm{MPa}$, respectively; the relative droplet velocity is assumed to be constant and equal to $10 \mathrm{~m} / \mathrm{s}$; the initial droplet radius and homogeneous temperature are assumed to be equal to $10 \mu \mathrm{m}$ and $300 \mathrm{~K}$, respectively.
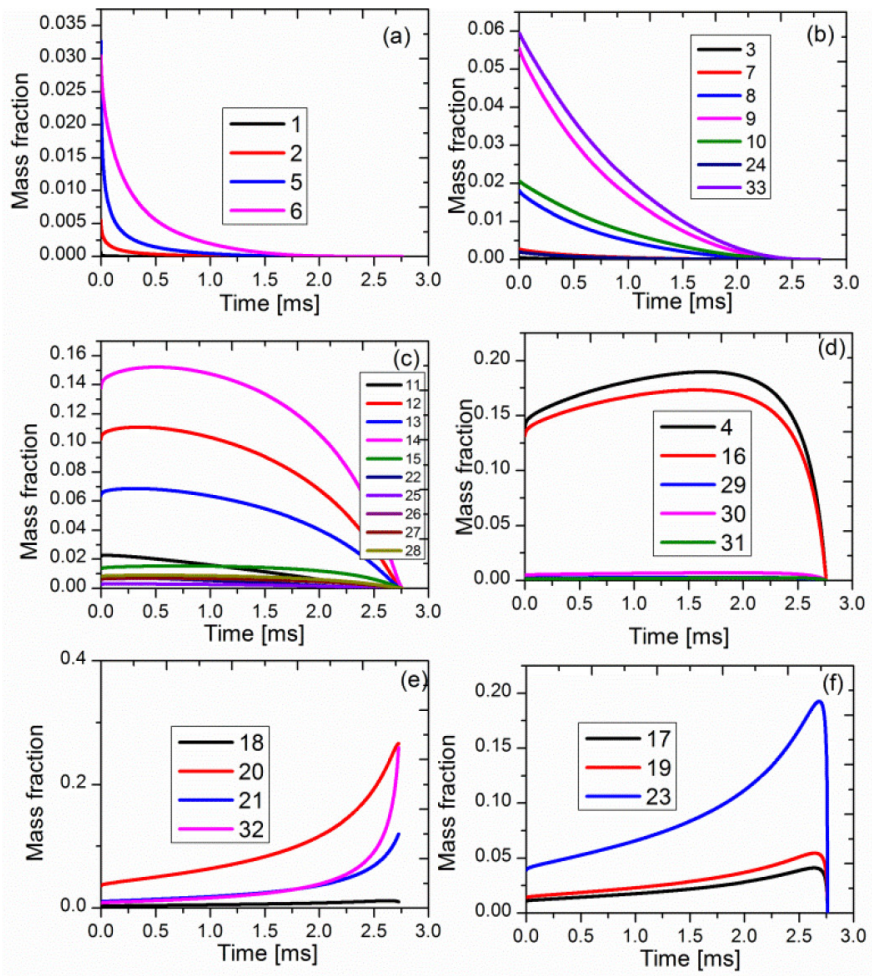

Figure 2. The liquid mass fractions of components of FACE I gasoline fuel at the droplet surface versus time for the same conditions as in Fig. 1 
Table 2. Mass and molar fractions of different surrogates of FACE I gasoline fuel.

\begin{tabular}{|c|c|c|c|c|c|c|c|c|c|c|}
\hline \multirow[b]{2}{*}{ component } & \multicolumn{2}{|c|}{$\begin{array}{c}\text { Surrogate } \\
1\end{array}$} & \multicolumn{2}{|c|}{$\begin{array}{c}\text { Surrogate } \\
2\end{array}$} & \multicolumn{2}{|c|}{$\begin{array}{c}\text { Surrogate } \\
3\end{array}$} & \multicolumn{2}{|c|}{$\begin{array}{c}\text { Surrogate } \\
4\end{array}$} & \multicolumn{2}{|c|}{$\begin{array}{c}\text { Surrogate } \\
5\end{array}$} \\
\hline & $\begin{array}{l}\mathrm{ma} \\
\mathrm{ss}\end{array}$ & $\begin{array}{l}\text { mo } \\
\text { le }\end{array}$ & $\begin{array}{l}\mathrm{ma} \\
\mathrm{ss}\end{array}$ & $\begin{array}{l}\text { mo } \\
\text { le }\end{array}$ & $\begin{array}{l}\mathrm{ma} \\
\mathrm{ss}\end{array}$ & $\begin{array}{l}\text { mo } \\
\text { le }\end{array}$ & $\begin{array}{l}\mathrm{ma} \\
\mathrm{ss}\end{array}$ & $\begin{array}{l}\text { mo } \\
\text { le }\end{array}$ & $\begin{array}{l}\mathrm{ma} \\
\mathrm{ss}\end{array}$ & $\begin{array}{l}\text { mo } \\
\text { le }\end{array}$ \\
\hline (6) i-pentane & $\begin{array}{c}6.9 \\
3\end{array}$ & $\begin{array}{l}10 . \\
47\end{array}$ & $\begin{array}{c}6.9 \\
3\end{array}$ & $\begin{array}{l}10 . \\
47\end{array}$ & $\begin{array}{c}6.9 \\
3\end{array}$ & $\begin{array}{l}10 . \\
47\end{array}$ & $\begin{array}{l}16 . \\
02\end{array}$ & $\begin{array}{l}20 . \\
07\end{array}$ & $\begin{array}{l}16 . \\
02\end{array}$ & $\begin{array}{l}20 . \\
07\end{array}$ \\
\hline $\begin{array}{l}\text { (14) } 3 \\
\text { methylhexane }\end{array}$ & $\begin{array}{l}37 . \\
14 \\
\end{array}$ & $\begin{array}{l}35 \\
71 \\
\end{array}$ & $\begin{array}{l}37 . \\
14 \\
\end{array}$ & $\begin{array}{l}35 \\
71 \\
\end{array}$ & $\begin{array}{c}0.0 \\
0 \\
\end{array}$ & $\begin{array}{c}0.0 \\
0\end{array}$ & $\begin{array}{l}24 . \\
03\end{array}$ & $\begin{array}{l}22 . \\
95\end{array}$ & $\begin{array}{l}24 . \\
03\end{array}$ & $\begin{array}{l}22 . \\
95\end{array}$ \\
\hline $\begin{array}{l}\text { (16) } 2,2,4 \\
\text { trimethylpentan } \\
\text { e }\end{array}$ & $\begin{array}{l}27 . \\
91\end{array}$ & $\begin{array}{l}25 . \\
12\end{array}$ & $\begin{array}{c}0.0 \\
0\end{array}$ & $\begin{array}{c}0.0 \\
0\end{array}$ & $\begin{array}{c}0.0 \\
0\end{array}$ & $\begin{array}{c}0.0 \\
0\end{array}$ & $\begin{array}{l}23 . \\
13\end{array}$ & $\begin{array}{l}20 . \\
54\end{array}$ & $\begin{array}{c}5.7 \\
6\end{array}$ & $\begin{array}{c}4.8 \\
4\end{array}$ \\
\hline $\begin{array}{l}\text { (20) } 2,3,4 \\
\text { trimethlpentane }\end{array}$ & $\begin{array}{c}5.7 \\
6\end{array}$ & $\begin{array}{c}4.8 \\
4\end{array}$ & $\begin{array}{c}5.7 \\
6\end{array}$ & $\begin{array}{c}4.8 \\
4\end{array}$ & $\begin{array}{c}5.7 \\
6\end{array}$ & $\begin{array}{c}4.8 \\
4\end{array}$ & $\begin{array}{c}7.4 \\
0\end{array}$ & $\begin{array}{c}6.2 \\
0\end{array}$ & $\begin{array}{c}0.0 \\
0\end{array}$ & $\begin{array}{c}0.0 \\
0\end{array}$ \\
\hline (23) toluene & $\begin{array}{c}6.3 \\
3 \\
\end{array}$ & $\begin{array}{c}6.0 \\
8\end{array}$ & $\begin{array}{c}6.3 \\
3 \\
\end{array}$ & $\begin{array}{c}6.0 \\
8\end{array}$ & $\begin{array}{c}6.3 \\
3 \\
\end{array}$ & $\begin{array}{c}6.0 \\
8\end{array}$ & $\begin{array}{c}4.6 \\
2\end{array}$ & $\begin{array}{c}4.9 \\
3 \\
\end{array}$ & $\begin{array}{c}4.6 \\
2 \\
\end{array}$ & $\begin{array}{c}4.9 \\
3 \\
\end{array}$ \\
\hline (33) Hexene-1 & $\begin{array}{l}15 \\
92\end{array}$ & $\begin{array}{l}17 . \\
77\end{array}$ & $\begin{array}{l}15 . \\
92\end{array}$ & $\begin{array}{l}17 . \\
77\end{array}$ & $\begin{array}{l}15 \\
92\end{array}$ & $\begin{array}{l}17 . \\
77\end{array}$ & $\begin{array}{c}5.9 \\
6\end{array}$ & $\begin{array}{c}6.7 \\
8\end{array}$ & $\begin{array}{c}5.9 \\
6\end{array}$ & $\begin{array}{c}6.7 \\
8\end{array}$ \\
\hline (4) n-heptane & $\begin{array}{c}0.0 \\
0 \\
\end{array}$ & $\begin{array}{c}0.0 \\
0 \\
\end{array}$ & $\begin{array}{l}27 . \\
91 \\
\end{array}$ & $\begin{array}{l}25 . \\
12 \\
\end{array}$ & $\begin{array}{l}27 . \\
91 \\
\end{array}$ & $\begin{array}{l}25 \\
12 \\
\end{array}$ & $\begin{array}{l}14 . \\
61 \\
\end{array}$ & $\begin{array}{l}14 . \\
43 \\
\end{array}$ & $\begin{array}{l}14 . \\
61 \\
\end{array}$ & $\begin{array}{l}14 . \\
43 \\
\end{array}$ \\
\hline $\begin{array}{l}\text { (13) } 2,3 \\
\text { dimethyl } \\
\text { pentane }\end{array}$ & $\begin{array}{c}0.0 \\
0\end{array}$ & $\begin{array}{c}0.0 \\
0\end{array}$ & $\begin{array}{c}0.0 \\
0\end{array}$ & $\begin{array}{c}0.0 \\
0\end{array}$ & $\begin{array}{l}37 \\
14\end{array}$ & $\begin{array}{c}35 . \\
71\end{array}$ & $\begin{array}{c}0.0 \\
0\end{array}$ & $\begin{array}{c}0.0 \\
0\end{array}$ & $\begin{array}{c}0.0 \\
0\end{array}$ & $\begin{array}{c}0.0 \\
0\end{array}$ \\
\hline $\begin{array}{l}(30) \\
\text { methylcyclohex } \\
\text { ane }\end{array}$ & $\begin{array}{c}0.0 \\
0\end{array}$ & $\begin{array}{c}0.0 \\
0\end{array}$ & $\begin{array}{c}0.0 \\
0\end{array}$ & $\begin{array}{c}0.0 \\
0\end{array}$ & $\begin{array}{c}0.0 \\
0\end{array}$ & $\begin{array}{c}0.0 \\
0\end{array}$ & $\begin{array}{c}4.2 \\
2\end{array}$ & $\begin{array}{c}4.0 \\
9\end{array}$ & $\begin{array}{c}4.2 \\
2\end{array}$ & $\begin{array}{c}4.0 \\
9\end{array}$ \\
\hline
\end{tabular}

The time evolution of droplet surface temperature and radius for FACE I fuel and 5 different surrogates are shown in Fig. 3 for the same conditions as in Fig. 1. Lines for FACE I are the same as shown in Fig. 1. It can be seen that the evaporation time predicted for Surrogate 1 and Surrogate 4 are indistinguishable from this of FACE I while Surrogate 2 and Surrogate 3 overpredicts the droplet lifetime and Surrogate 5 underpredicts the lifetime of the fuel droplet. One could see the difference between Surrogate 4 and Surrogate 5 is the existence of 2,3,4 trimethylpentane. Ignoring this component by merging it with 2,2,4 trimethylpentane leads to approximately $10 \%$ difference in the evaporation time. This is can be explained by the difference in the evaporation characteristics between both components as shown in Fig. 3c,d.

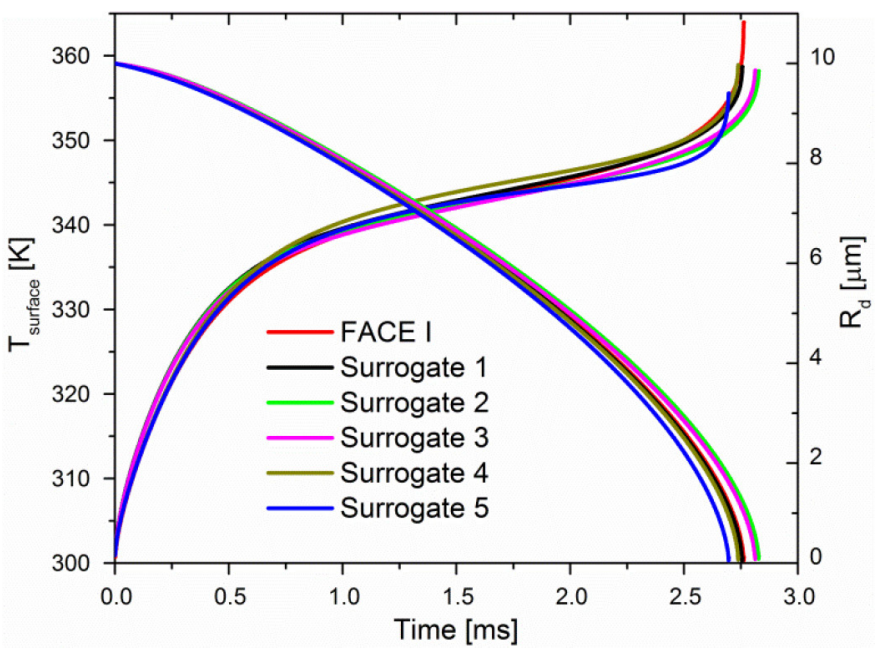

Figure 3. Droplet surface temperatures and radii versus time for FACE I and 5 different surrogates. The values of other input parameters are the same as in Figs. 2-3.

Another approach for formulating surrogate of FACE I, using measured distillation profile, is also considered. The components of this surrogate are shown in Table 3 . A comparison of the measured distillation profile and calculated profiles for distillation surrogate and Surrogate 4 is shown in Fig. 4 . The results reveal that the predicted distillation surrogate agrees well with the measured profile with maximum absolute error less than $3 \%$, however the maximum absolute error for the predicted distillation profile of Surrogate 4 is less than $5 \%$.

Table 3. Mass and molar fractions of the distillation surrogate.

\begin{tabular}{|l|l|l|}
\hline Species & Mass fraction & Mole fraction \\
\hline 2-Methyl butane & 0.08 & 0.11 \\
\hline 2-methyl hexane & 0.28 & 0.28 \\
\hline 1-Hexene & 0.05 & 0.06 \\
\hline n-Heptane & 0.12 & 0.12 \\
\hline 2,2,4-Trimethylpentane & 0.40 & 0.35 \\
\hline cyclohexane & 0.04 & 0.05 \\
\hline toluene & 0.04 & 0.04 \\
\hline
\end{tabular}

A comparison of the calculated droplet surface temperature and radius for FACE I, distillation surrogate and Surrogate 4 along with three droplets of Surrogate 4 with initial droplet radii of 5, 10 and 15 $\mu \mathrm{m}$ are shown in Fig. 5. It can be noticed that the evaporation time predicted for distillation surrogate is lower than FACE I by approximately $10 \%$ while the evaporation time for Surrogate 4 is indistinguishable from this of FACE I droplet. The mass fractions of different hydrocarbon types for FACE I, Surrogate 4 and distillation surrogate is presented in Table 4. This comparison shows that Surrogate 4 has the same mass fractions of FACE I while there are differences for distillation surrogate case. Increase of Surrogate 4 droplet radius from 5 to $10 \mu \mathrm{m}$ is shown to increase the droplet lifetime by more than $200 \%$ while increasing it from 10 to $15 \mu \mathrm{m}$ increases the droplet lifetime by approximately $100 \%$. The increase in the relative velocity is expected to enhance the evaporation process for all considered surrogates.

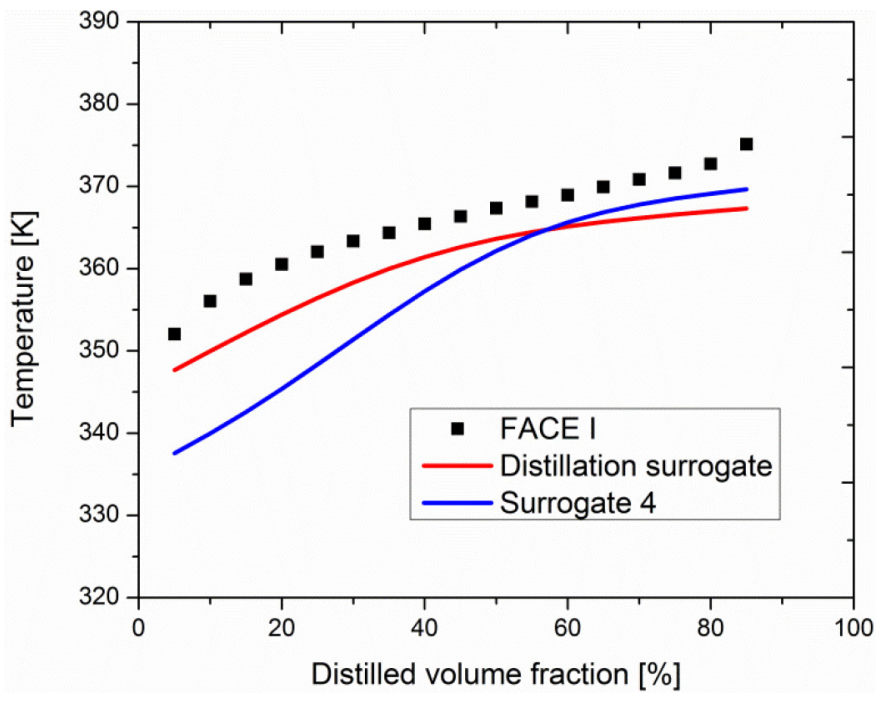

Figure 4. Comparison of measured distillation profile and predicted ones for distillation surrogate and Surrogate 4. 
Table 4. Mass fractions of different hydrocarbon types for FACE I, Surrogate 4 and distillation surrogate.

\begin{tabular}{|l|c|c|c|}
\hline Hydrocarbon Type & FACE I & Surrogate 4 & Distillation surrogate \\
\hline Paraffins & 0.14 & 0.14 & 0.11 \\
\hline Iso-paraffins & 0.7 & 0.7 & 0.74 \\
\hline Olefins & 0.07 & 0.07 & 0.06 \\
\hline Naphthenes & 0.04 & 0.04 & 0.05 \\
\hline Aromatics & 0.05 & 0.05 & 0.04 \\
\hline
\end{tabular}

To investigate the ability of the proposed physical surrogates to mimic different target properties including those of chemical surrogates, the $\mathrm{H} / \mathrm{C}$ ratio, molecular weight and $\mathrm{RON}$ were calculated and presented in Table 5 . RON is calculated using two different approaches; linear by mole and non-linear approach as suggested by Ghosh et al. [29]. It can be noticed that Surrogate 4 has values of molar mass, $\mathrm{H} / \mathrm{C}$ ratio and RON close to those of FACE I than those of distillation surrogate.
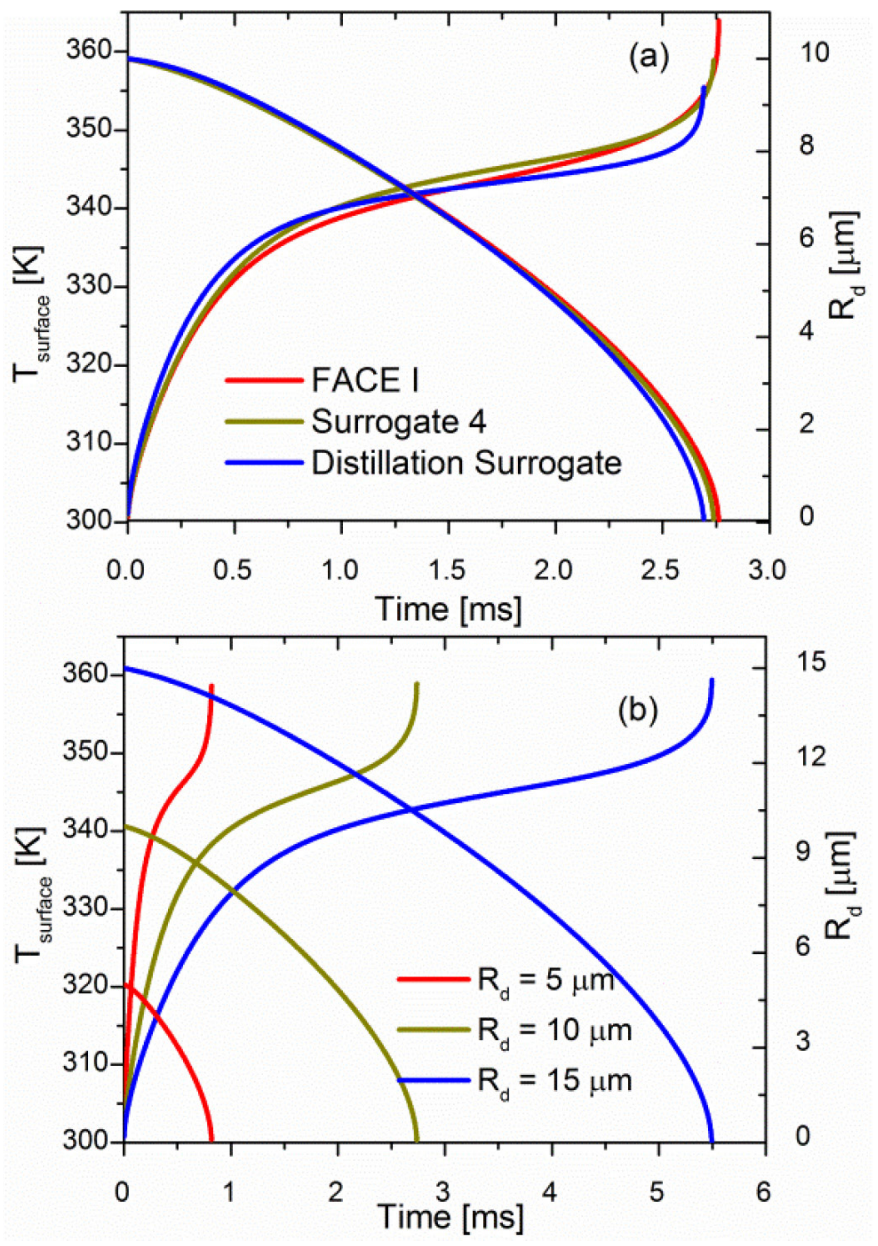

Figure 5. Comparison of predicted droplet surface temperature and radius of a) FACE I, distillation surrogate and Surrogate 4 at the same conditions as in Fig. 1; b) three droplets of Surrogate 4 with 5, 10 and $15 \mu \mathrm{m}$ initial radius.
Table 5. Comparison of molar mass, H?C ratio and RON for FACE I and different surrogates.

\begin{tabular}{|c|c|c|c|c|c|c|c|}
\hline & $\begin{array}{c}\text { FA } \\
\text { CE } \\
\text { I }\end{array}$ & $\begin{array}{c}\text { Surro } \\
\text { gate 1 }\end{array}$ & $\begin{array}{c}\text { Surro } \\
\text { gate 2 }\end{array}$ & $\begin{array}{c}\text { Surro } \\
\text { gate 3 }\end{array}$ & $\begin{array}{c}\text { Surro } \\
\text { gate 4 }\end{array}$ & $\begin{array}{c}\text { Surro } \\
\text { gate 5 }\end{array}$ & $\begin{array}{c}\text { Dist. } \\
\text { Surroga } \\
\text { te }\end{array}$ \\
\hline $\begin{array}{c}\mathrm{MW} \\
{[\mathrm{kg} / \mathrm{kmol}} \\
]\end{array}$ & $\begin{array}{c}95.4 \\
5\end{array}$ & 97.90 & 94.72 & 94.72 & 96.06 & 96.06 & 99.87 \\
\hline HC & 2.22 & 2.17 & 2.18 & 2.18 & 2.21 & 2.21 & 2.21 \\
\hline $\begin{array}{c}\text { RON- } \\
\text { non- } \\
\text { linear }\end{array}$ & 69.9 & 77.83 & 73.42 & 86.99 & 73.34 & 73.34 & 73.54 \\
\hline $\begin{array}{c}\text { RON- } \\
\text { linear }\end{array}$ & $\begin{array}{c}69.9 \\
6\end{array}$ & 75.60 & 50.48 & 68.82 & 69.34 & 69.34 & 69.73 \\
\hline $\begin{array}{c}\text { MON- } \\
\text { non- } \\
\text { linear }\end{array}$ & $\begin{array}{c}68.3 \\
6\end{array}$ & 80.89 & 76.77 & 79.69 & 70.60 & 70.60 & 71.43 \\
\hline $\begin{array}{c}\text { MON- } \\
\text { linear }\end{array}$ & $\begin{array}{c}68.3 \\
6\end{array}$ & 78.20 & 53.38 & 66.95 & 68.11 & 68.11 & 69.06 \\
\hline
\end{tabular}

\section{Conclusions}

Heating and evaporation of FACE I single droplet was studied using the ETC/ED model that accounts for finite thermal conductivity, finite mass diffusivity and recirculation inside the droplet. Then the evaporation characteristics of the components of FACE I was analyzed and 5 different surrogates were proposed. Among them, Surrogate 4, the eight component surrogate was shown to be a good candidate to mimic evaporation characteristics. The distillation profile for FACE I was measured and 7 components distillation based surrogate was proposed. The distillation profile for Surrogate 4 was calculated and was found to have maximum absolute error of 5\%. The values of $\mathrm{H} / \mathrm{C}$ ratio, molar mass and $\mathrm{RON}$ were calculated for all surrogates and compared with those of FACE I. The comparison revealed that Surrogate 4 has closer values of these target properties to those of FACE I than other surrogates. It could be concluded that Surrogate 4 can be consider a reasonable surrogate of FACE I that mimic evaporation characteristics, $\mathrm{H} / \mathrm{C}$ ratio, molar mass and $\mathrm{RON}$.

\section{References}

1. Anand K., Ra Y., Reitz R., Bunting B. "Surrogate model development for fuels for advanced combustion engines," Energy \& Fuels 2011; 25: 1474-1484.

2. in, Co-ordinating Research Council (CRC), 2015.

3. Pitz, W., Cernansky, N., Dryer, F., Egolfopoulos, F. et al., "Development of an Experimental Database and Chemical Kinetic Models for Surrogate Gasoline Fuels," SAE Technical Paper 2007-01-0175, 2007, doi:10.4271/2007-01-0175.

4. Javed T., Nasir E.F., Es-sebbar E.-t., Farooq A. "A comparative study of the oxidation characteristics of two gasoline fuels and an n-heptane/iso-octane surrogate mixture," Fuel 2015; 140: 201-208.

5. Sarathy S.M., Kukkadapu G., Mehl M., Wang W., et al., "Ignition of alkane-rich FACE gasoline fuels and their surrogate mixtures," Proceedings of the Combustion Institute 2015; 35: 249-257. 
6. Gauthier B.M., Davidson D.F., Hanson R.K. "Shock tube determination of ignition delay times in full-blend and surrogate fuel mixtures," Combustion and Flame 2004; 139: 300-311.

7. Andrae J.C.G. "Development of a detailed kinetic model for gasoline surrogate fuels," Fuel 2008; 87: 2013-2022.

8. Andrae J.C.G., Brinck T., Kalghatgi G.T. "HCCI experiments with toluene reference fuels modeled by a semidetailed chemical kinetic model," Combustion and Flame 2008; 155: 696-712.

9. Violi A., Yan S., Eddings E., Sarofim A., et al., "Experimental formulation and kinetic model for JP-8 surrogate mixtures," Combustion Science and Technology 2002; 174: 399-417.

10. Kukkadapu G., Kumar K., Sung C.-J., Mehl M., et al., "Autoignition of gasoline and its surrogates in a rapid compression machine," Proceedings of the Combustion Institute 2013; 34: 345-352.

11. Ahmed A., Khurshid M., Naser N., Badra J., et al.,, "Surrogate fuel formulation for light naphtha combustion in advanced combustion engines," in: European Combustion Meeting, Hungary, 2015.

12. Ahmed A., Goteng G., Shankar V.S., Al-Qurashi K., et al., "A computational methodology for formulating gasoline surrogate fuels with accurate physical and chemical kinetic properties," Fuel 2015; 143: 290-300.

13. Su M., Chen C. "Heating and evaporation of a new gasoline surrogate fuel: A discrete multicomponent modeling study," Fuel 2015; 161: 215-221.

14. Ra Y., Reitz R.D. "A combustion model for multi-component fuels using a physical surrogate group chemistry representation (PSGCR)," Combustion and Flame 2015.

15. Abdelghaffar W., Elwardany A., Sazhin S. "Modeling of the processes in diesel engine-like conditions: Effects of fuel heating and evaporation," Atomization and Sprays 2010; 20: 737-747.

16. Tamim J., Hallett W. "A continuous thermodynamics model for multicomponent droplet vaporization," Chemical Engineering Science 1995; 50: 2933-2942.

17. Sazhin S., Elwardany A., Krutitskii P., Castanet G., et al., "A simplified model for bi-component droplet heating and evaporation," International Journal of Heat and Mass Transfer 2010; 53: 4495-4505.

18. Abianeh O.S., Chen C. "A discrete multicomponent fuel evaporation model with liquid turbulence effects," International Journal of Heat and Mass Transfer 2012; 55: 6897-6907.

19. Sazhin S., Krutitskii P., Abdelghaffar W., Sazhina E., et al., "Transient heating of diesel fuel droplets," International Journal of Heat and Mass Transfer 2004; 47: 3327-3340.

20. Castanet G., Lavieille P., Lemoine F., Lebouché M., et al., "Energetic budget on an evaporating monodisperse droplet stream using combined optical methods: Evaluation of the convective heat transfer," International journal of heat and mass transfer 2002; 45: 5053-5067.

21. Abramzon B., Sirignano W. "Droplet vaporization model for spray combustion calculations," International journal of heat and mass transfer 1989; 32: 1605-1618.
22. Sazhin S., Elwardany A., Krutitskii P., Deprédurand V., et al., "Multi-component droplet heating and evaporation: numerical simulation versus experimental data," International Journal of Thermal Sciences 2011; 50: 1164-1180.

23. Bruno T.J., Ott L.S., Smith B.L., Lovestead T.M. "Complex fluid analysis with the advanced distillation curve approach," Analytical chemistry 2009; 82: 777-783.

24. Knop V., Loos M., Pera C., Jeuland N. "A linear-by-mole blending rule for octane numbers of n-heptane/iso-octane/ toluene mixtures," Fuel 2014; 115: 666-673.

25. Mueller C.J., Cannella W.J., Bruno T.J., Bunting B., et al., "Methodology for formulating diesel surrogate fuels with accurate compositional, ignition-quality, and volatility characteristics," Energy \& Fuels 2012; 26: 3284-3303.

26. Japanwala S., Chung K.H., Dettman H.D., Gray M.R. "Quality of distillates from repeated recycle of residue," Energy \& fuels 2002; 16: 477-484.

27. Elwardany A., Sazhin S. "A quasi-discrete model for droplet heating and evaporation: Application to Diesel and gasoline fuels," Fuel 2012; 97: 685-694.

28. Lenhert D.B., Miller D.L., Cernansky N.P., Owens K.G. "The oxidation of a gasoline surrogate in the negative temperature coefficient region," Combustion and flame 2009; 156: 549-564.

29. Ghosh P., Hickey K.J., Jaffe S.B. "Development of a detailed gasoline composition-based octane model," Industrial \& engineering chemistry research 2006; 45: 337-345.

\section{Contacts}

Dr. Ahmed Elwardany

Clean Combustion Research Center

King Abdullah University of Science and Technology

Saudi Arabia

Ahmed.elwardani@kaust.edu.sa

Telephone: +966544700974

\section{Acknowledgments}

Research reported in this publication was supported by King Abdullah University of Science and Technology (KAUST) and Saudi Aramco under the FUELCOM program.

\section{Definitions/Abbreviations}

DHA - Detailed hydrocarbon analysis

DI - Direct injection

ED - Effective diffusivity

ETC - Effective thermal conductivity

FACE - Fuels for advanced combustion engines

H/C - Hydrogen-to-carbon

RON - Research octane number 


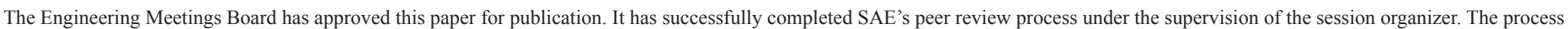
requires a minimum of three (3) reviews by industry experts.

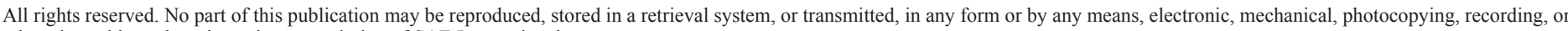
otherwise, without the prior written permission of SAE International.

Positions and opinions advanced in this paper are those of the author(s) and not necessarily those of SAE International. The author is solely responsible for the content of the paper.

ISSN 0148-7191

http://papers.sae.org/2016-01-0878 